\title{
РОЛЬ ТЕАТРАЛЬНОЙ МЕТАФОРЫ В НЕМЕЦКОМ ПОЛИТИЧЕСКОМ ДИСКУРСЕ
}

\section{THE ROLE OF THEATER METAPHOR IN GERMAN POLITICAL DISCOURCE}

\section{E. Lavristscheva}

Summary: The article deals with the theoretical and practical problems of the description of German political discourse. Special attention is paid to the theater metaphor as one of the most common types of conceptual metaphor represented in the political discourse. The analysis of the frames of the metaphorical model "politics is theatre" is given in the article.

Keywords: conceptual metaphor, political discourse, frame, metaphorical model, metaphor functions.

\author{
Лаврищева Екатерина Владимировна \\ к.филол.н., ФГБОУ ВО «Елецкий государственный \\ университет им. И.А. Бунина» \\ eklav@mail.ru
}

Аннотация: В статье раскрываются теоретические и практические проблемы описания немецкого политического дискурса. Особое внимание уделяется театральной метафоре как одному из наиболее распространенных типов концептуальной метафоры, представленной в политическом дискурсе. В статье дается анализ фреймов метафорической модели «политика - это театр».

Ключевые слова: концептуальная метафора, политический дискурс, фрейм, метафорическая модель, функции метафоры.

инструментом при поиске решений проблемных ситуаций: «Метафорическое мышление в политике является признаком кризисного мышления, мышления в сложной проблемной ситуации, разрешение которой требует значительных усилий от когнитивной системы человека по усвоению новых знаний и переработке их для построения множества вариантов действий и выбора правильной альтернативы» [Баранов, Казакевич 1991:17].

А.П. Чудинов также отмечает, что в политической коммуникации метафора выступает важным средством познания и объяснения мира, а также эффективным средством прагматического воздействия на сознание массовой аудитории [Чудинов 2013:63].

Нами был проведен анализ статей на политическую тему из журналов Spiegel Online, Die Zeit, а также выступлений немецких политиков. Анализ языкового материала показывает, что наиболее частотной метафорой в текстах СМИ является социальная метафора (более 40 \% от общего количества проанализированного материала), которая представлена метафорическими моделями, основанными на понятийных сферах социальной субсферы: криминальная метафора («политика - это преступление»), военная метафора («политика - это война»), театральная метафора («политика - это театр»), спортивная/игровая метафора («политика - это спорт», «политика - это игра»), метафора путешествия («политика - это путешествие»).

В нашем исследовании мы остановимся на метафорической модели «политика - это театр», которая получила широкое распространение в публицистических текстах. Театр, как сфера-источник реализует эмотивную функ- 
цию, то есть воздействует на эмоционально-волевую сферу адресата и создает соответствующее отношение к рассматриваемым политическим реалиям и процессам. Для описания данной метафорической модели, используются следующие фреймы:

1) Фрейм «Публика и прием, оказываемый спектаклю»

Данный фрейм репрезентируется такими лексическими единицами, как das Publikum, das Fiasko: Schlecht aber, dass beim Publikum der Eindruck entsteht, in der Politik ginge es tatsächlich um nichts anderes als um Seehofers Neurosen, um die mentale Obdachlosigkeit der kompletten SPD und um die Frage, wer wessen Widersacher ist. (Die Zeit, 04.01.2018, Nr. 02); Für Labour dürfte die Wahl zu einem Fiasko werden. (Die Zeit, 19.04.2017).

\section{2) Фрейм «Элементы представления»}

Как любое зрелищное представление, политическая деятельность состоит из отдельных частей, этапов и эпизодов. Для описания данной метафорической модели используются такие лексические единицы как das Szenario, spielen: In einem zweiten, negativen Szenario verscherzt es sich Österreich mit der Europäischen Union, die FPÖ untergräbt die freie Presse und das Land bekommt am Ende das Ausländerproblem... (Die Zeit, 23.12.2017); Seehofer spielte Oppositionsführer, stichelte, stänkerte und drohte sogar mit einer Verfassungsklage gegen eine Bundesregierung, an der seine Partei selbst beteiligt war. (Die Zeit, 06.01.2018).

Метафорическое употребление лексемы «das Szenario» имплицитно (указывает на наличие организаторов (т.е. тех, кто пишет сценарий, продумывает и разрабатывает определенные действия, выступает вдохновителем, распределяет роли и т.д.) и исполнителей тех или иных действий. При этом реализуются такие прагматические смыслы как «несамостоятельность», «неискренность», «зависимость от организаторов».

3) Фрейм «Театральное здание и театральный реквизит»

В рамках данного фрейма политические решения рассматриваются как запланированное событие, которое начинается «из-за кулис», скрыто от глаз публики (т.е. народа), и при необходимости выходит на политическую сцену или арену, при этом метафорически реализуется представление о том, что народ (публика), а иногда и другие участники политического процесса, не могут повлиять на принятие того или иного политического решения, т.к. все решения применяются скрытно, «за кулисами»: Hinter den Kulissen läuft die Krisendiplomatie auf Hochtouren. (Der Spiegel. 02.03.2020); Einerseits möchte man der Geltungssucht der Täter keine Bühne bereiten und damit gar Trittbrettfahrer animieren. (Rede von Frank-Walter Steinmeier, 10.03.2020).

4) Фрейм «Вид зрелища и жанр представления»

Современные политические события зачастую обозначаются как тот или иной зрелищный жанр, например: die Show, die Farce, das Drama и другие. Само наименование зрелища и его жанра оказывает влияние на формирование эмотивных смыслов: события и их герои оцениваются в соответствии с традицией жанpa: Sie konnten neulich beim Treffen der Afrikanischen Union mit dem russischen Präsidenten in Sotschi sehen, dass das Ganze begleitet war von einer großen Show von militärischen Gegenständen. (Rede von Angela Merkel, 27.11.2019); Europas noch verbliebener Anspruch als normativer Akteur wäre sonst nach außen wie nach innen eine komplette Farce gewesen. (Die Zeit, 20.12.2017); Sie fordert viele Opfer und treibt Zigtausend Menschen, darunter Tausende Kinder, in die Flucht. Es ist ein humanitäres Drama mit großen geopolitischen Folgen. (Rede von Angela Merkel, 17.10.2019).

В данном примере реализуется пейоративная (отрицательная, уничижительная) оценка событий, подобное словоупотребление способствует формированию негативных эмоций и ассоциаций. Важную роль играет акцентирование таких сем, как «комичное», «несерьезное, ничего не значащее», «краткосрочное», «высмеивающее человеческую глупость».

5) Фрейм «Люди театра»

В политическом дискурсе достаточно широко представлены организаторы и исполнители. Для их обозначения чаще всего используются такие лексемы как der Held, die Marionette, die One-Man-Show: Wenn einige Beobachter jetzt sagen, dass bei uns Faschismus droht, dann ist das für mich eine Farce. Wenn jemand meint, Kaczyński würde in seinem Zimmer sitzen und Politiker wie Marionetten aufstellen, dann versteht er wirklich nichts von polnischer Politik. (Die Zeit, 06.12.2017, Nr. 51); Was Janukowitsch sagt, kommt gut an; auch beim amerikanischen Botschafter in Kiew, John Tefft, mit dem Manafort sich angefreundet hat (und der später USBotschafter in Moskau wird). Während sich die politischen Helden der Orangen Revolution in Grabenkämpfen zerfleischen, gibt Janukowitsch den geläuterten Staatsmann. (Die Zeit, 29.12.2017, Nr. 01); Offen und hitzig debattiert auch das Parlament, dessen Gewicht nach einer vielversprechenden Gründungsphase immer mehr abgenommen hat, dank Arafat, der als Meister der One-man-Show auf Abgeordnetenbeschlüsse keinen besonders großen Wert zu legen scheint. (Die Zeit, 16.05.1997, Nr. 21); Die Regierung wird Suthep morgen Helden spielen lassen, sagte er. Das wird seine Show. (Der Spiegel. 17.02.2014); Die Prognose zum Wirtschaftswachstum gibt es einmal im halben Jahr, der Termin taugt nicht gerade zur Schärfung des eigenen Profils. Es sei denn, man heißt Sigmar Gabriel und nutzt die Bühne für eine einstündige One-ManShow. (Der Spiegel. 14.04.2014).

Подобная метафора несет, как правило, негативные эмоции, указывает на неискренность и лицемерие политика. Как отмечает А.П. Чудинов, в сознании масс политик должен быть героем, а не играть роль героя, так как любая «неестественность» вредит имиджу политического деятеля [Чудинов 2013:50].

Таким образом, театральная метафора находит свое отражение в политике, представляя политическую деятельность как сценарий или заранее запланированное 
шоу, отражающие двуличие или неискренность участников политической деятельности. Также данная метафорическая модель иллюстрирует «действие за кадром», а именно политические действия и решения политиков, которые скрыты от граждан, то есть те, которые не выносятся на публику.

Широкое использование метафор в политическом дискурсе объяснятся тем, что метафора позволяет более красочно представить картину мира, происходящие политические процессы, насыщая официальный текст различными выразительными образами, способными надолго сохраниться в памяти. Впоследствии эти образы становятся предметом цитирования, воспроизведения, обсуждения, то есть, реальным инструментом политического воздействия.

\section{ЛИТЕРАТУРА}

1. Баранов, А.Н. Дескрипторная теория метафоры [Электронный ресурс] / А.Н. Баранов. - М. : Языки славянской культуры, 2014 . - 633 с.

2. Баранов, А.Н., Казакевич, Е.Г. Парламентские дебаты: традиции и новации // Сов. полит. яз. (от ритуала к метафоре) / А. Н. Баранов, Е.Г. Казакевич. - М.: Знание, 1991. -63 с.

3. Чудинов, А.П. Очерки по современной политической метафорологии: Монография / Урал. гос. пед. ун-т. - Екатеринбург, 2013. - 176 с.

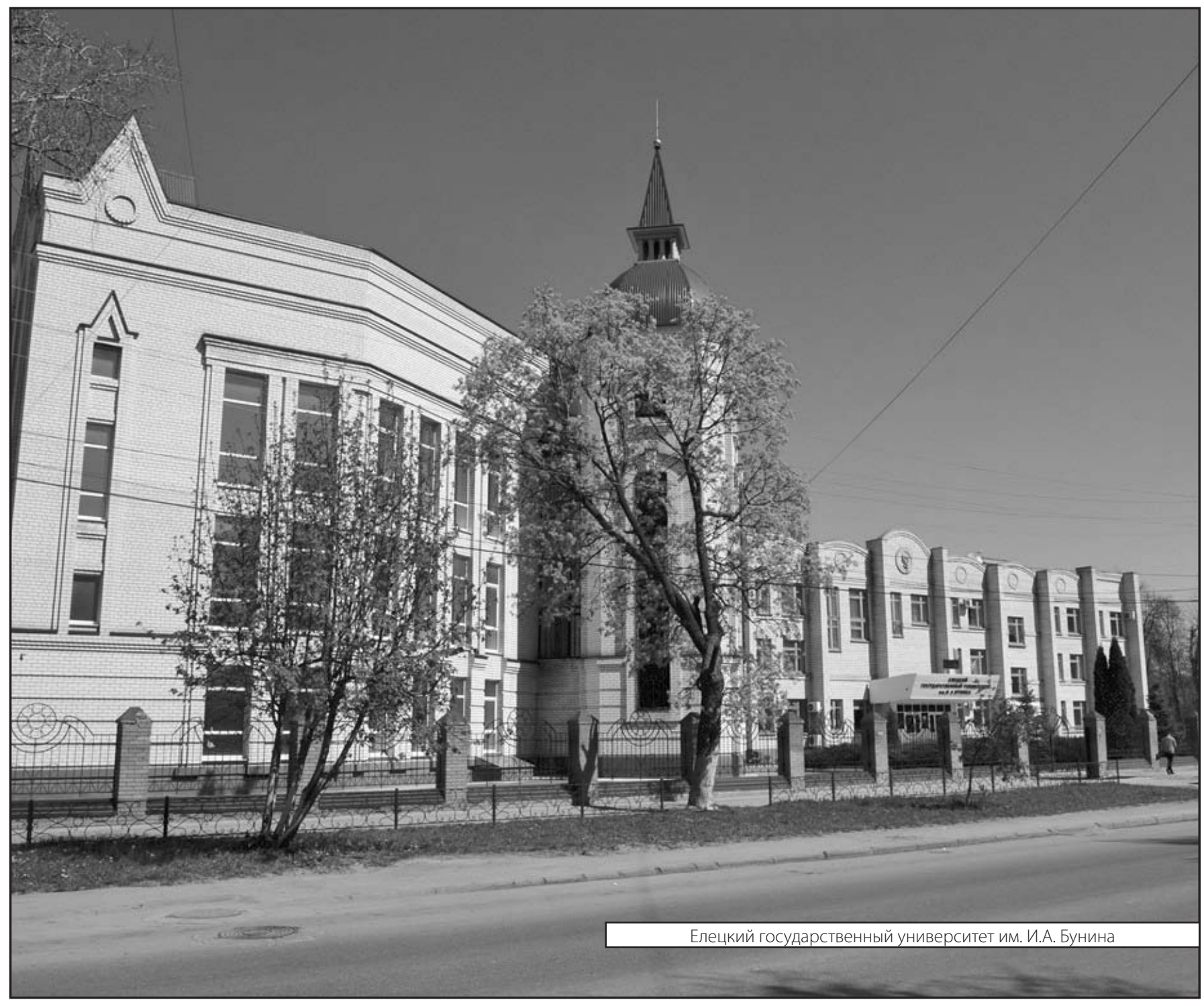

